\title{
MANFAAT LATIHAN RELAKSASI HYPNOBIRTHING PADA PROSES PERSALINAN KALA I
}

\author{
Yayuk Nuryanti ${ }^{1,2}$, Wenny Artanty Nisman ${ }^{2}$, Risanto Siswosudarmo ${ }^{3}$ \\ ${ }^{1}$ Mahasiswa Program Studi Magister Keperawatan \\ Fakultas Kedokteran Universitas Gadjah Mada, Yogyakarta \\ ${ }^{2}$ Departemen Keperawatan Anak dan Maternitas, Fakultas Kedokteran \\ Universitas Gadjah Mada, Yogyakarta \\ ${ }^{3}$ Rumah Sakit Umum Pusat Dr. Sardjito, Yogyakarta \\ E-mail: yayuk.nuryanti@yahoo.com,mbaktanty@yahoo.com, hrisanto@yahoo.com
}

\begin{abstract}
ABSTRAK
Pendahuluan: Hypnobirthing merupakan salah satu teknik autohipnosis yang merupakan bagian dari tindakan mandiri perawat untuk menyiapkan proses persalinan dalam mengurangi kecemasan dan nyeri persalinan. Tujuan penelitian: untuk mengetahui perbedaan nyeri persalinan dan lama persalinan kala I antara kelompok ibu hamil yang dilatih relaksasi hypnobirthing dengan yang tidak dilatih. Metode: desain penelitian secara quasi eksperimen, sampel diambil secara consecutive sejumlah 82 orang di 4 BPM Kabupaten Klaten. Data dianalisis dengan uji chi square dan regresi logistik. Hasil penelitian didapatkan perbedaan persentase antara kelompok perlakuan dengan kelompok kontrol, untuk rasa tidak nyeri perbedaan $23 \%$ dengan $R R 2,94(95 \% \mathrm{Cl} 1,17-7,41) \mathrm{p}$ $=0,013$. Pada kala I tidak lama perbedaan 19\% dengan RR 1,26 (95\% Cl 1,01-1,57) $p=0,035$. Hasil ini menunjukkan kemungkinan tidak nyeri hampir 3 kali dan kemungkinan kala I tidak lama hampir 1,5 kali pada kelompok perlakuan. Analisis regresi logistik menunjukkan bahwa relaksasi hypnobirthing dan multiparitas memberi efek yang signifikan untuk mengurangi nyeri persalinan dan mempersingkat lama kala I. Kesimpulan: Latihan relaksasi hypnobirthing memberi manfaat untuk mengurangi nyeri persalinan dan memperpendek lama kala I pada proses persalinan normal. Saran: Hypnobirthing perlu diberikan kepada ibu hamil sebagai bagian dari perawatan kehamilan untuk menyiapkan psikologis ibu dalam menghadapi persalinan. Untuk pengembangan penelitian selanjutnya, perlu ditambahkan faktor-faktor yang memengaruhi nyeri persalinan.

Kata Kunci: hypnobirthing, persalinan, nyeri persalinan, persalinan kala I.
\end{abstract}

\section{BENEFITS OF HYPNOBIRTHING EXERCISE IN THE FIRST STAGE OF LABOR ABSTRACT}

Introduction: Hypnobirthing is a technique of autohypnosis which is a part of self-nursing care to prepare a more comfortable labor process. Objective: To identify difference in labor pain, duration of the first stage of labor between pregnant mothers trained with hypnobirthing and those who were not trained. Methods: This study employed a quasi experimental design involving 4 private midwives in Klaten Regency. Samples were 82 mothers taken consecutively. Data were statistically analyzed using Chi square-test and logistic regression. Results: There were differences between the treatment group and the control group. The difference in feeling no pain was $23 \%$ with $R R$ of 2.94 (95\% Cl 1.17-7.41) $p=0.013$; the difference in the short duration of the first stage of labor was $19 \%$ with $R R$ of $1.26(95 \% \mathrm{Cl} 1.01-1.57) p=0.035$. The results indicated that the probability of feeling no pain was almost three times and the probability of short duration of the first stage of labor was one and a half times in the treatment group. The logistic regression showed that hypnobirthing and multiparity had a significant effect on reducing pain during labor process and shorthening duration of the first stage of labor. Conclusion: Hypnobirthing exercise was beneficial in reducing pain and shorthening duration of the first stage of labor process. Suggestion: Hypnobirthing should be given to pregnant women as part of prenatal care for psychological condition of mothers in facing the labor. Further research needs to be include factors that affect pain labor.

Keywords: hypnobirthing, labor process, pain labor, first stage of labor 


\section{LATAR BELAKANG}

Persalinan dipandang dari segi psikologis merupakan suatu kejadian penuh dengan stres pada sebagian besar ibu bersalin yang menyebabkan peningkatan rasa nyeri, takut, dan cemas. Primipara mengalami proses persalinan lebih lama daripada multipara sehingga primipara mengalami nyeri persalinan lebih lama pula. Hal tersebut menyebabkan mereka lebih letih, persepsi nyeri meningkat dan rasa takut lebih parah yang dapat meningkatkan intensitas nyeri (Bobak, dkk., 2005). Sarmana (2004) menyatakan bahwa responden meminta persalinan seksio sesaria karena alasan rasa sakit pada persalinan spontan. Salfariani dan Nasution (2012) dalam penelitiannya didapatkan hasil 59,1 persen seksio sesaria dari faktor kecemasan pada persalinan normal.

Dewasa ini sudah banyak metode penatalaksanaan nyeri persalinan baik farmakologis maupun nonfarmakologis. Salah satu metode nonfarmakologis yaitu hypnobirthing. Metode relaksasi hypnobirthing didasarkan pada keyakinan bahwa setiap perempuan memiliki potensi untuk menjalani proses melahirkan secara alami, tenang, dan nyaman (tanpa rasa sakit) (Kuswandi, 2012). Intervensi keperawatan untuk mengatasi nyeri menurut Nursing Intervenstions Classification (NIC) salah satunya adalah manajemen nyeri dengan mengajarkan teknik nonfarmakalogis yaitu hipnosis (Wilkinson dan Ahem, 2012).

Masalah yang diajukan dalam penelitian ini adalah apakah manfaat latihan relaksasi hypnobirthing pada proses persalinan. Tujuan yang akan dicapai adalah untuk mengetahui manfaat latihan relaksasi hynobirthing dengan melihat perbedaan persentase pada kelompok ibu hamil yang dilatih relaksasi hypnobirthing dengan yang tidak dilatih relaksasi hypnobirthing, dalam hal nyeri persalinan dan lama persalinan kala I.

\section{METODE}

Penelitian ini dengan rancangan quasi eksperimen, desain post test-only non equivalent control group dilakukan di 4 Bidan Praktek Mandiri (BPM) Kabupaten Klaten. Kelompok perlakuan merupakan kelompok yang dilatih relaksasi hypnobirthing, sedangkan kelompok kontrol merupakan kelompok yang tidak dilatih, di mana kedua kelompok sama-sama mendapatkan asuhan persalinan normal. Latihan dilakukan 40-60 menit seminggu sekali, selama 4 minggu. Selain itu responden melakukan latihan mandiri di rumah. Pengambilan sampel menggunakan teknik consecutive sampling.

Sampel ditetapkan dengan kriteria inklusi ibu hamil trimester 3 dengan umur kehamilan 35-36 minggu, janin tunggal hidup, presentasi kepala, belum ada his dan tanda-tanda persalinan dan bersedia menjadi responden. Berdasar kriteria tersebut, didapat 84 orang bersedia menjadi responden, yang dibagi menjadi 2 kelompok. Tetapi dalam proses penelitian kelompok perlakuan ada 2 orang dikeluarkan karena mengalami persalinan patologis.

Pengumpulan data dilakukan oleh asisten peneliti menggunakan kuesioner dan lembar observasi. Variabel yang dinilai meliputi nyeri persalinan menggunakan skala nyeri numerik, yang telah dilakukan uji validitas dan reliabilitas oleh Gloth (2001) dan lama persalinan kala I. Data dianalisis menggunakan uji statistik chi square, dan regresi logistik. 
HASIL

Karakteristik responden didapatkan bahwa dari 82 responden sebagian besar dengan usia yang tidak berisiko (72 persen), primipara (51 persen), dan berpendidikan tinggi (75,6 persen). Berdasarkan hasil analisis homogenitas didapatkan $p>0,05$ sehingga dapat disimpulkan bahwa kedua kelompok penelitian adalah homogen.

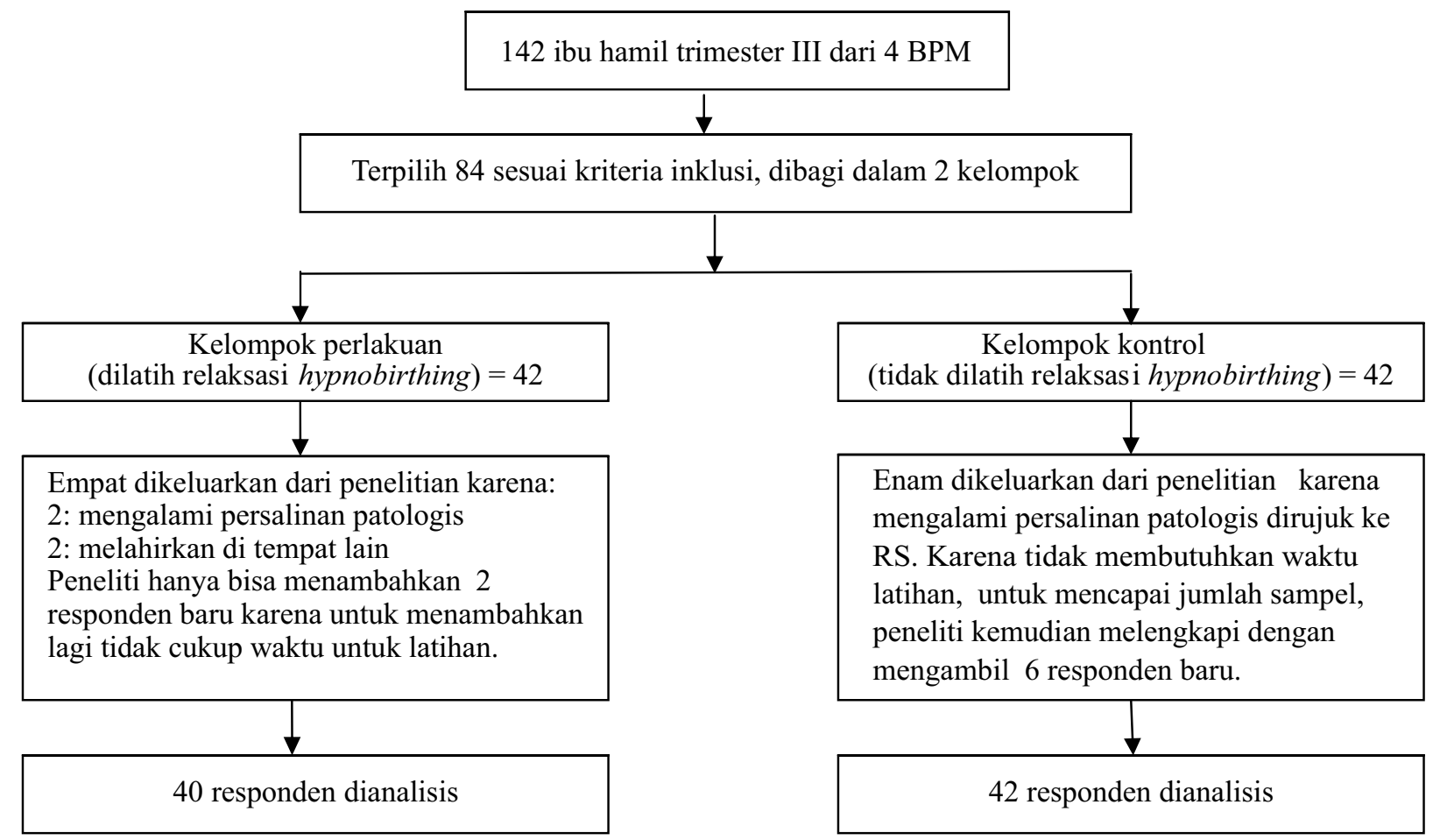

Gambar 1. Skema pengambilan sampel

\section{Nyeri Persalinan}

Hasil penelitian didapat kejadian tidak nyeri pada kelompok perlakuan lebih banyak dibanding kelompok kontrol, dengan perbedaan sebesar $23 \%$, nilai $\mathrm{RR} 2,94$ dengan $95 \% \mathrm{Cl} 1,17-7,41$ dengan nilai $p<0,05$ (Tabel 1). Hal ini menunjukkan bahwa ibu hamil yang dilatih relaksasi hypnobirthing maka dalam proses persalinan normalnya kemungkinan untuk tidak nyeri mencapai hampir 3 kali dibanding ibu yang tidak dilatih relaksasi hypnobirthing.

Tabel 1.Perbandingan kejadian tidak nyeri persalinan berdasar kelompok penelitian

\begin{tabular}{lcccccc}
\hline \multirow{2}{*}{ Kelompok } & \multicolumn{2}{c}{ Tidak Nyeri } & Nyeri & \multicolumn{2}{c}{ RR (95\% Cl) } & \multirow{2}{*}{$\boldsymbol{p}$} \\
\cline { 2 - 6 } & $\mathrm{n}$ & $\%$ & $\mathrm{n}$ & $\%$ & & \\
\hline \multirow{2}{*}{ Perlakuan } & 14 & 35 & 26 & 65 & $\begin{array}{l}2,94 \\
(1,17-\end{array}$ & 0,013 \\
Kontrol & & & & & $7,41)$ & \\
\hline
\end{tabular}


Tabel 2. Analisis regresi logistik: pengaruh hypnobirthing terhadap nyeri persalinan dengan mengontrol variabel luar (paritas)

\begin{tabular}{ccc}
\hline \multirow{2}{*}{ Variabel } & Tidak nyeri & $\boldsymbol{p}$ \\
\cline { 2 - 2 } $\begin{array}{c}\text { Kelompok } \\
\text { Perlakuan }\end{array}$ & $4,45 \%$ Cl) & \\
$\quad$ Kontrol & $1,37-14,44)$ & 0,013 \\
$\begin{array}{c}\text { Paritas } \\
\text { Multipara }\end{array}$ & 1 & \\
$\quad$ Primipara & $3,30(1,05-10,37)$ & 0,041 \\
\hline
\end{tabular}

Hasil analisis regresi logistik diperoleh mengalami tidak nyeri hampir sebesar 4,5 bahwa ibu multipara persentase kejadian kali dibanding ibu yang tidak dilatih relaksasi tidak nyeri lebih banyak dibanding ibu hypnobirthing (Tabel 2). Secara statistik, primipara dengan perbedaan sebesar 18 kondisi ini bermakna dengan nilai $p<0,05$. persen. Hasil penelitian menunjukkan Hal ini menunjukkan bahwa latihan relaksasi bahwa latihan relaksasi hypnobirthing yang hypnobirthing memberi manfaat yang baik diberikan pada paritas yang sama, efek terhadap penurunan nyeri persalinan. pada proses persalinan normal kemungkinan

Tabel 3. Perbandingan lama persalinan berdasar kelompok penelitian

\begin{tabular}{|c|c|c|c|c|c|c|}
\hline \multirow{3}{*}{ Variabel } & \multicolumn{4}{|c|}{ Kelompok } & \multirow{3}{*}{ RR (95\% Cl) } & \multirow{3}{*}{ p } \\
\hline & \multicolumn{2}{|c|}{ Perlakuan } & \multicolumn{2}{|c|}{ Kontrol } & & \\
\hline & $\mathbf{n}$ & $\%$ & $\mathbf{n}$ & $\%$ & & \\
\hline \multicolumn{7}{|l|}{ Kala 1 lama } \\
\hline Tidak & 36 & 90 & 30 & 71,4 & $1,26(1,01-1,57)$ & 0,034 \\
\hline Ya & 4 & 10 & 12 & 28,6 & & \\
\hline
\end{tabular}

\section{Proses Persalinan Kala I}

Hasil penelitian menunjukkan bahwa kejadian kala I tidak lama pada kelompok perlakuan lebih banyak daripada kelompok kontrol, dengan perbedaan hampir 19 persen dengan RR $1,26(95 \% \mathrm{Cl} 1,01-$
1,57) dan $p=0,034$ (Tabel 3). Hasil ini menunjukkan bahwa bila ibu hamil yang dilatih relaksasi hypnobirthing kemungkinan untuk mengalami kala I tidak lama mencapai hampir 1,5 kali dibanding ibu yang tidak dilatih relaksasi hypnobirthing. 
Tabel 4. Analisis regresi logistik: pengaruh hypnobirthing terhadap lama persalinan kala I dengan mengontrol variabel luar (paritas)

\begin{tabular}{lcc}
\hline \multicolumn{1}{c}{ Variabel } & $\begin{array}{c}\text { Kala I tidak lama } \\
\text { OR }(95 \% \mathrm{Cl})\end{array}$ & $p$ \\
\hline $\begin{array}{l}\text { Kelompok } \\
\text { Perlakuan }\end{array}$ & $3,85(1,10-13,51)$ & 0,035 \\
$\quad$ Kontrol & 1 & \\
$\begin{array}{l}\text { Paritas } \\
\text { Multipara }\end{array}$ & $2,71(0,82-9,01)$ & 0,103 \\
$\quad$ Primipara & 1 & \\
\hline
\end{tabular}

Hasil analisis regresi logistik didapatkan bahwa latihan relaksasi hypnobirthing dapat mempersingkat lama persalinan kala I 3,85 kali lebih besar daripada tidak latihan (Tabel 4). Hal ini menunjukkan bahwa dengan latihan relaksasi hypnobirthing dapat memberi manfaat dalam mempersingkat persalinan kala I.

\section{DISKUSI}

Nyeri merupakan perasaan subjektif seseorang. Setiap orang mempunyai ambang nyeri yang berbeda meskipun diberi intervensi yang sama. Hypnobirthing adalah metode persalinan yang memungkinkan ibu melahirkan bayi dengan aman, tanpa obat, dan mampu melakukannya dengan nyaman (Mongan, 2007). Hypnobirthing sebagai teknik relaksasi yang memberikan sugesti positif mampu meningkatkan ketenangan jiwa saat menjalani kehamilan dan proses persalinan. Kata-kata atau sugesti positif akan memicu serangkaian perasaan sehingga menumbuhkan keyakinan dan reaksi yang dapat memberi semangat dan dorongan untuk berperilaku. Reeder, dkk (2011) menjelaskan bahwa relaksasi merupakan suatu perlibatan aktif pikiran tubuh yang memerlukan kesadaran, konsentrasi, dan latihan. Latihan yang teratur atau pengulangan teknik relaksasi dibutuhkan untuk memelihara respons terkondisi terhadap keadaan.

Abbasi, dkk (2009) dalam penelitian dengan pendekatan kualitatif mendapatkan salah satu tema besar hasil bahwa hipnosis untuk menghilangkan rasa sakit saat persalinan. Peneliti lain yaitu Semple dan Newburn (2011), menjelaskan terhadap 5 studi dalam tinjauan Cochrane bahwa ibu hamil pada kelompok hipnosis sedikit yang menggunakan anti nyeri dibanding ibu pada kelompok kontrol. Merujuk dari hasil penelitian tersebut menunjukkan bahwa latihan hypnobirthing pada ibu hamil trimester 3 mampu meningkatkan ketenangan. Ketenangan yang dialami akan meminimalkan kecemasan dan ketakutan sehingga mengurangi rasa nyeri pada persalinan normal.

Ibu primipara yang menggunakan teknik hipnosis diri mengalami tingkat nyeri yang lebih rendah daripada kelompok yang tidak menggunakan hipnosis diri (Harahap, 2009). Mudah tidaknya seseorang mengatasi nyeri tergantung pengalamannya di masa lalu (Potter dan Perry, 2005). Beberapa faktor yang berpengaruh terhadap persalinan yaitu pemahaman tentang keyakinan, nilainilai, dan kenyataan akan rasa sakit saat persalinan akan mempersempit persepsi nyeri yang dirasakan (Lowdermilk, dkk., 2012). Berdasarkan beberapafaktor tersebut, akhirnya pasien akan berkeyakinan bahwa 
wanita saat mengalami proses persalinan pasti akan merasakan sakit. Keyakinan seseorang bisa dirubah dengan usaha yang dilakukan oleh tenaga kesehatan dan pasien itu sendiri. Usaha yang bisa dilakukan adalah dengan latihan yang berkelanjutan untuk membentuk pola aktif yang dapat digunakan ketika proses persalinan. Hal inimenunjukkan bahwa latihan relaksasi hypnobirthing akan memberi manfaat yang baik pada ibu hamil yang mendekati persalinan.

Lowdermilk, dkk (2012) menjelaskan bahwa kala I persalinan merupakan tahap dilatasi, dimulai dengan awitan kontraksi persalinan yang teratur dan diakhiri dengan dilatasi serviks secara lengkap. Merujuk penelitian sebelumnya dari Harahap (2009), ibu primipara yang menggunakan teknik relaksasi hipnosis diri menunjukkan rata-rata lama persalinan yang lebih pendek daripada ibu yang tidak menggunakan relaksasi hipnosis diri. Pada peneliti lain, Batbual (2010) menjelaskan bahwa lama kala I lebih singkat dengan metode hypnobirthing daripada tanpa hypnobirthing. Penelitian yang sudah dilakukan tersebut membuktikan bahwa metode hypnobirthing dapat mempersingkat waktu lama persalinan kala I.

Psikologis ibu merupakan salah satu faktor esensial yang memengaruhi dalam proses persalinan, yaitu kondisi kejiwaan ibu yang meliputi persiapan fisik untuk melahirkan, pengalaman persalinan yang lalu, dukungan orang-orang terdekat, dan integritas emosional ibu. Kondisi ibu yang rileks selama persalinan mendukung kontraksi yang baik, efektif, dalam mendorong janin ke arah jalan lahir sehingga mulut rahim akan terbuka (Bobak, dkk., 2005). Hal ini menunjukkan bahwa ibu hamil menjelang persalinan membutuhkan kondisi psikologis yang baik. Untuk mencapai kondisi tersebut dibutuhkan dukungan baik dari pasangan, keluarga, maupun orang lain. Salah satu bentuk dukungan orang lain dalam mempersiapkan psikologis ibu dalam menghadapi persalinan yang nyaman ialah tenaga kesehatan yang melatih teknik relaksasi hypnobirthing.

Landolt dan Milling (2011), menjelaskan bahwa hipnosis merupakan metode efektif, mengurangi rasa sakit, dan kala satu lebih pendek. Hal ini menunjukkan bahwa lama persalinan kala I dapat dipengaruhi oleh kondisi psikologis pasien. Persalinan dapat berjalan secara wajar dan lancar apabila didukung dengan ketenangan dan kondisi rileks sehingga otot rahim berkontraksi dengan baik dan teratur. Apabila ibu berada dalam keadaan rileks selama persalinan, kontraksi yang terjadi akan mendorong janin ke arah jalan lahir dengan membuka mulut rahim dengan mudah. Apabila ibu tidak rileks karena tegang menghadapi proses persalinan, otot-otot dalam punggung akan menjadi kaku sehingga proses pembukaan jalan lahir menjadi lebih lama. Untuk itu, persiapan psikologi selama kehamilan akan membantu ibu hamil dalam proses persalinan. Perawatan antenatal yang baik dan program latihan relaksasi hipnobirthing merupakan salah satu bentuk perawatan kehamilan yang mendukung lancarnya persalinan.

\section{SIMPULAN}

Latihan relaksasi hypnobirthing bermanfaat dalam mengurangi nyeri persalinan, persentase kejadian tidak nyeri lebih banyak terjadi pada kelompok hypnobirthing dibanding kelompok tidak latihan hypnobirthing. Latihan relaksasi Hypnobirthing bermanfaat dalam mempersingkat lama kala I, persentase kejadian kala I tidak lama lebih banyak pada kelompok hypnobirthing daripada kelompok tidak latihan hypnobirthing. 
DAFTAR PUSTAKA

Abbasi, M., Ghazi, F. Harrison, A.B. Sheikhvatan, M \& Mohammadyari. 2009. "The Effect of Hypnosis on Pain Relief During Labor and Childbirth in Iranian Pregnant Women". International Journal of Clinical and Experimental Hypnosis. Volume 57, Issue 2, 2009.

Batbual, B. 2010. Pengaruh Hypnobirthing (melahirkan dengan hipnosis) terhadap lama persalinan kala satu di Daerah Istimewa Yogyakarta. Tesis Prodi IImu Kedokteran Klinik Minat Utama Maternal Perinatal, UGM, Yogyakarta.

Bobak, I.M., Lowdermilk, D.L., dan Jensen, M.G., 2005, Buku Ajar Keperawatan Maternitas Edisi 4, EGC, Jakarta.

Gloth. 2001. "The Functional Pain Scale: Reliability, Validity, and Responsiveness in An Elderly Population". JAMDA. Volume 2, Issue 3, pages 110-114, May 2001.

Harahap, D. 2009. Pengaruh Tekhnik Hipnosis Diri terhadap Tingkat Nyeri dan Lama Persalinan Ibu Primipara di RS Ananda Bekasi Jawa Barat. www.lontar. ui.ac.id. Diakses tanggal 9 Maret 2013.

Kuswandi, L. 2012. Keajaiban HypnoBirthing: Panduan Praktis Melahirkan Alami, Lancar, \& Tanpa Rasa Sakit. Pustaka Bunda, Jakarta.

Landot, A.S., dan Milling, L.S. 2011. Clinical Psychological Review: The Efficacy of Hypnosis as An Intervention for Labor and Delivery Pain: A Comprehensive Methodological Review. Volume 31, Issue 6, August 2011, Pages 1022-1031. Lowdermilk, D.L., Perry, S.E., Cashion, K., dan Alden, K.R. 2012. Maternity\&Women Health Care. 10 th Edition. Elseiver, Mosby.

Mongan, M.F. 2007. Hypnobirthing the Mongan Method. Bhuana IImu Populer, Jakarta.

Potter, P.A. dan Perry, A.N. 2005. Buku Ajar Fundamental Keperawatan: Konsep, Proses, dan Praktik. Edisi 4. Volume 3. EGC, Jakarta.

Reeder, S.J, Martin, L.L., dan Griffin, D.K. 2011. Keperawatan Maternitas Kesehatan Wanita, Bayi, \& Keluarga. EGC, Jakarta.

Salfariani, I. dan Nasution, SS. 2012. "Faktor Pemilihan Persalinan Sectio Caesaria Tanpa Indikasi Medis di RSU Bunda Thamrin Medan".

Sarmana. 2004. "Determinan Non Medis dalam Permintaan Persalinan Sectio Caesarea di RS St. Elisabeth Medan".

Semple, A. and Newburn, M. (2011), Research Overview: Self-Hypnosis for Labour and Birth. Journal on Preparing Parents for Birth and Early Parenthood, December 2011.

Wilkinson, J.M., Ahern, N.C. 2012. Buku Saku Diagnosis Keperawatan Edisi 9: Diagnosis NANDA, Intervensi NIC, Kriteria Hasil NOC. EGC, Jakarta. 